\title{
Usos de empréstimos em português e em polaco: exemplos dos blogues femininos
}

\author{
Uses of Loanwords in Portuguese and in Polish: Examples \\ from Women's Blogs
}

EDyta JABŁonka [edyta.jablonka@umcs.pl]
Uniwersytet Marii Curie-Skłodowskiej, Polónia

\section{RESUMO}

Com este estudo, pretende-se apresentar algumas tendências nas línguas portuguesa e polaca relacionadas com o uso de empréstimos. Analisando o corpus selecionado a partir dos blogues femininos, destacam-se algumas características da ocorrência dos empréstimos, assim como se observam alguns aspetos morfossintáticos. Deve-se ter em conta também que a linguagem usada nos textos em questão reflete o desenvolvimento da sociedade, tratando-se frequentemente dos casos da atividade profissional das autoras. No entanto, também se repara no uso quotidiano de empréstimos presentes nos comentários escritos pelos leitores dos blogues escolhidos para a análise. Tomando em conta que cada língua precisa de renovar o seu acervo lexical para funcionar como ferramenta de comunicação, devido ao aparecimento de novos objetos e fenómenos, considera-se o empréstimo um dos elementos mais importantes deste processo e as necessidades de uma língua constituem um critério indispensável na introdução das palavras estrangeiras em diferentes contextos.

\section{Palavras-chave}

Empréstimo; português; polaco; blogue

\begin{abstract}
The aim of this study is to present some trends in the Portuguese and Polish languages related to the use of loanwords. By analyzing the corpus selected from the women's blogs, we highlight some characteristics of the occurrence of loanwords, as well as the morphosyntactic aspects. It should also be noted that the language used in the texts analyzed reflects the development of society, often dealing with the professional activity of the authors. However, we also observe the daily use of loanwords present in the comments written by readers of the blogs. Taking into account that each language needs to renew its lexical collection to function as a communication tool due to the emergence of new objects and phenomena, borrowing is considered to be one of the very important elements of this process and the need for a language is a criterion indispensable in introducing foreign words into different contexts.
\end{abstract}

\section{KEYWORDS}

Loanword; Portuguese, Polish, Blog 


\section{Introdução}

Através dos séculos, as línguas estrangeiras enriqueceram o acervo lexical do português e do polaco. A influência de línguas tais como o francês, o inglês ou o italiano marcou várias fases da evolução de ambas as línguas e, com certeza, até hoje é atual. A entrada dos empréstimos no léxico destas duas línguas realiza-se de maneira natural, faz parte do processo da evolução da língua, o que observamos tanto na história do léxico português como do polaco. ${ }^{1} \mathrm{O}$ léxico é de natureza pluridimensional e constitui uma componente importante da língua cuja função é "produzir, armazenar, processar e transmitir signos que os falantes usam como matéria-prima na elaboração de raciocínios e na construção de enunciados verbais" (Rio-Torto 2006: 2). O processo de importação de novas unidades lexicais é muito produtivo nas línguas portuguesa e polaca e somos testemunhas deste processo em vários ambientes e meios de comunicação, onde frequentemente são usados para chamar a atenção ou surpreender. Novos termos que aparecem na língua contribuem para a sua evolução, indicam novas direções. Aparecem sempre novos fatores sociais e políticos que motivam modificações lexicais. Atualmente, estas transformações são muito rápidas graças ao acesso aos meios de comunicação e aos equipamentos dos quais podemos dispor facilmente para termos acesso à rede. Alves (2004) afirma que "o léxico de um idioma, entretanto, não se amplia exclusivamente por meio do acervo já existente: os contactos entre as comunidades linguísticas refletem-se lexicalmente e constituem uma forma de desenvolvimento do conjunto lexical de uma língua" (Alves 2004: 72). Segundo a linguista, a fase neológica do estrangeirismo começa com a integração na língua recetora, que se manifesta pela adaptação gráfica, fonética, morfológica ou semântica. As adaptações morfológicas realizam-se quando os empréstimos iniciam o processo de derivação ou composição (por exemplo do substantivo stress derivam o verbo 'estressar' e o adjetivo 'estressado'). Quanto à adaptação semântica, ela relaciona-se com a mudança do significado da palavra emprestada. O decalque também pode ser considerado como uma forma de integração do empréstimo sendo a versão literal da unidade lexical estrangeira.

\section{Quadro teórico}

No caso do empréstimo, segundo Guilbert (1975), trata-se de uma unidade lexical sentida como externa à língua; um termo de origem estrangeira deixa de ser neologismo a partir do momento em que entra no sistema linguístico da língua recetora, ou seja, quando deixa de ser percebido como termo estrangeiro" (Guilbert 1975: 95-97).

Lamberti (1999: 28) considera que para classificar uma palavra como empréstimo, ela deve apresentar alguns traços característicos: deve ser uma palavra de origem estrangeira, assim como uma palavra estrangeira ainda não adaptada à língua recebedora; deve ser palavra atestada como estrangeira, mas ter a sua forma completamente adaptada à gramática da língua importadora, decalcada ou híbrida; ser tanto um termo de uso generalizado, o que significa que o seu uso se tornou comum numa comunidade falante. Correia, por sua vez, define o empréstimo como: processo

1 No entanto, devemos ter em conta que a influência das línguas como o russo ou o alemão teve muito mais impacto no polaco do que no português. Atualmente, os empréstimos em ambas as línguas provêm principalmente do inglês, o que é visível também nos textos citados no presente estudo. 
de transferência de uma unidade lexical de um registo linguístico para outro dentro da mesma língua (empréstimo interno), ou de uma língua para outra (empréstimo externo); unidade que resulta do processo de transferência anteriormente descrito (Correia 1999: 53).

Os estrangeirismos podem causar problemas a todas as pessoas de uma comunidade falante, quando são demasiado especializadas, quando provocam dificuldades na pronúncia, na escrita, o que faz com que às vezes apareçam várias versões gráficas de uma mesma palavra estrangeira. No uso gramatical, pode haver problemas com a flexão das palavras estrangeiras, com o género e número. Em geral, os falantes de uma língua são capazes de reconhecer as palavras estranhas para o seu sistema linguístico, e costumam alterar a pronúncia e, em consequência, a morfologia da palavra, por isso, há hesitações por exemplo na formação do plural. Porém, a mudança do léxico a expansão por meio de empréstimos - parece-nos antes positiva, pois, segundo Alves (1998), os neologismos "resultam de uma criação motivada, ditada pela necessidade de dominação inerente ao desenvolvimento das ciências e das técnicas" (Alves 1998: 25).

Falando das causas do aparecimento dos empréstimos, temos de ter em consideração diferentes fatores. Weinreich (1968), como uma das razões do aparecimento dos empréstimos, coloca a existência dos homónimos na língua importadora, criação dos empréstimos resultante da necessidade de resolver a possível ambiguidade, a necessidade contínua de criar novos sinónimos em certos campos lexicais, ou bem a perceção que alguns campos lexicais não são suficientemente diferenciados.

Portanto, uma língua, para funcionar como ferramenta de comunicação, tem de se enriquecer e renovar o seu acervo lexical, por causa do aparecimento de novos objetos e fenómenos. $\mathrm{O}$ empréstimo é um dos elementos muito importantes deste processo. Os que são necessários enriquecem a língua, designam novos objetos, usam-se em terminologia especializada e normalmente não têm equivalentes na língua vernácula. Os desnecessários são usados para efeitos estilísticos e geralmente têm equivalentes portugueses e polacos. A condição básica da aceitação dos estrangeirismos é a compreensão do seu significado, da pronúncia e da ortografia.

Achamos todas estas considerações importantes por formarem a base teórica da segunda parte do nosso estudo em que passamos à apresentação dos exemplos reunidos no nosso corpus, selecionado a fim de facilitar o trabalho relacionado com a verificação dos fenómenos da língua em uso. Os exemplos escolhidos permitem estudar os padrões reais de uso de língua em textos naturais. Convém salientar também que o nosso corpus é bastante variado, pois contém os exemplos retirados das línguas portuguesa (na variante europeia e brasileira) e polaca. Decidimos realizar a pesquisa sobre os empréstimos com base nos exemplos encontrados através da Internet, nomeadamente, em três blogues redigidos por mulheres.

\section{Papel dos blogues femininos}

A nossa escolha baseia-se na pressuposição que a Internet é hoje o meio mais comum de informação e comunicação no mundo inteiro, por isso, para os puristas pode parecer um perigo por divulgar mais a língua inglesa, mas para os "inovadores" pode ser uma fonte de pesquisas muito rica. Por esta razão, a nossa atenção centra-se no vocabulário dos blogues. No aspeto linguístico, analisa-se de que maneira as unidades lexicais provenientes das outras línguas se introduzem ao acervo lexical do português e do polaco atuais. Escolhemos o método comparativo entre 
o português europeu, o português brasileiro e o polaco, tendo em consideração as atitudes conservadoras e inovadoras nestes países. Podemos então considerar que estudamos a língua como fenómeno social e como testemunho das alterações linguísticas e socioculturais. O uso dos itens lexicais demonstra as necessidades e atitudes das pessoas que usam a Internet como meio de comunicação e de contacto com o mundo.

Não é fácil definir o que é um blogue, tratando-se de um género bastante diferenciado, que evolui sempre e ganha novas formas, como p.ex. vlogs (videoblogs, que evoluem também em filmes publicados nas redes sociais). Segundo Crystal (2006), o blogue é um diário pessoal, mas também há muitos blogues mais gerais. Myers repara que o blogue não se define pelo seu conteúdo, mas pelas aplicações resultantes do mesmo, elementos que influenciam na formação social e na construção da identidade: "blogs are genres of texts defined not so much by their form or content as by the kinds of uses to which they are put, and the ways these uses construct social and identities and communities" (Myers 2009: 15).

$\mathrm{Na}$ investigação relacionada com os blogues, geralmente notam-se duas tendências de análise: são tratados como género tipicamente relacionado com a Internet, ou são comparados com os géneros discursivos tradicionais, ou seja, com os diários tradicionais ou artigos. A linguagem dos blogues também é específica porque o autor é o único responsável pelo conteúdo do seu blogue. Frequentemente, a linguagem dos blogues é muito simples, coloquial ou tem características próprias, o que significa que é caraterizada pelo uso dos termos especializados formados pelos mesmos autores dos blogues. ${ }^{2}$

Os blogues nasceram no mundo virtual que exigia uma nova maneira de comunicação porque testemunhava as transformações que continuam até agora. A maneira como é usada a língua nos blogues permite-nos ver quais são as mudanças que estão a ocorrer na sociedade. O desenvolvimento da tecnologia tem possibilitado o aparecimento de novas técnicas de comunicação. Para muitos blogueiros, os seus blogues também se tornaram uma profissão, um emprego a tempo inteiro, e graças aos seus textos muitos ficaram famosos não somente no mundo virtual, mas são tratados como pessoas influentes ou celebridades. Na era da Internet, os mass media tradicionais são cada vez mais substituídos por canais disponíveis na rede. Para publicar lá não é preciso ser um profissional - praticamente cada pessoa é capaz de fazê-lo. Por isso, os blogues podem ser uma fonte muito rica do material estudado no nosso trabalho porque nos permitem observar quais são as tendências atuais nas alterações ocorrentes nas línguas. Os blogues mais populares são capazes de atrair mais público do que os jornais, por isso, a sua influência torna-se mais forte, o que já foi observado por Crystal (2006). ${ }^{3}$

2 Those who blog, bloggers, carry out the activity of blogging, setting up a blogsite with a unique web address in order to do so. They may also locate their page within a bigger site, which takes blog feeds from many sources, and includes other (non-blog) material. As bloggers gain experience, they will compile a blogroll listing their favourite links to other blogs, often shown as a sidebar on their screen. If they dart about from one site to another, they are engaging in blog hopping. If their blog contains a request to readers (e.g. for contributions), it may be called a bleg (a "begging blog"). If a blog goes on for too long, the writer may be described as having blogorrhea. If a topic or site attracts a considerable amount of online attention, the result is a blogstorm or blog swarm. Those who are wise in the ways of blogs are sometimes called the blogoise or blogerati. The totality of all blogsites is known as the blogosphere (Crystal 2006: 238-239).

3 Wright (2008: 179-182) sugere várias soluções para criar um blogue popular: ser autêntico, apaixonado, escrever com frequência, colocar muitos links, comentar outros blogues, divertir-se ao criar o seu blogue, ultrapassar os limites, inventar títulos que chamam a atenção dos leitores. 
Usar a Internet como meio de comunicação também tem grande importância por constituir uma situação específica entre o destinatário e o autor do comunicado, oferece a possibilidade do fluxo rápido de informação e, afinal, qualquer pessoa pode publicar o seu texto tal como quiser, usando a língua que quiser, sem restrições, interagindo com os visitantes. Os blogues, além de apresentarem as opiniões dos autores ou as notícias, tornaram-se um novo canal de comunicação e uma ferramenta de marketing. Os blogues femininos constituem um caso específico porque as mulheres estão atentas às novas tendências, utilizando as redes sociais e os blogues para partilhar e adquirir informações (Laruccio 2014). Usam o blogue como uma ferramenta muito importante de comunicação com o público, principalmente com o público feminino. Fornecendo informações sobre as marcas ou os produtos, entram em interação com as leitoras através dos comentários. Por esta razão, deve-se ter em conta os textos nos blogues, diariamente visitados por milhares de pessoas, o que já foi notado pelas empresas que procuram a cooperação com as blogueiras mais populares. Reparemos, então, na função destacada da mulher dentro da sociedade de consumo e na Internet. Apesar de os sítios consultados se destinarem ao público feminino e serem redigidos pelas mulheres, a nossa pesquisa não se limita às unidades lexicais pertencentes ao domínio da moda, mas também cuidados de saúde e de beleza, acessórios, culinária, ou desporto.

Os blogues femininos até agora têm sido pouco estudados: os trabalhos encontrados referem-se sobretudo aos aspetos relacionados com a publicidade e as questões económicas, pois para muitas mulheres ter um blogue significa simplesmente trabalhar. As blogueiras têm como objetivo melhorar a qualidade de relacionamento entre as empresas e as consumidoras. As leitoras, por sua vez, acreditam que diferentes produtos ou atividades sugeridos nos blogues são de confiança, por isso, o blogue gera o efeito de boca-a-boca. As mulheres participam na rede de maneira muito ativa e os blogues, além de dar conselhos e ajudá-las, contribuem para o desenvolvimento das mulheres em geral e também do desenvolvimento nos meios de comunicação.

Para os objetivos do presente trabalho, foram escolhidos exemplos de três blogues considerados mais populares em Portugal, no Brasil e na Polónia. Devido ao número muito grande de blogues existentes no espaço virtual, decidimos limitar-nos apenas a estes três como mais representativos e mais visitados diariamente por milhares de pessoas do mundo inteiro. ${ }^{4}$ Trata-se, nomeadamente, dos blogues seguintes: o blogue português www.apipocamaisdoce.sapo.pt, da jornalista portuguesa Ana Garcia Martins, empresária e autora de cinco livros, que ganhou os títulos do Blog do Ano duas vezes, em 2018 e 2017; o blogue brasileiro www.garotasestupidas.com, de Camila Coutinho, cujo blogue em 2017 entrou na lista BoF500 de Business of Fashion que elege as personalidades mais importantes no mundo da moda e foi mencionado como único não escrito em inglês; o terceiro é o blogue polaco www.hpba.pl/blog, redigido por Anna Lewandowska, desportista, empresária e esposa do famoso jogador de futebol polaco.

Passando à análise mais detalhada, comecemos por mencionar algumas observações de caráter geral e os aspetos comuns para todos os blogues observados. Do ponto de vista morfossintático, alguns empréstimos selecionados sofrem adaptações do género e número, e registamos também alguns empréstimos formados pelos processos de composição e derivação. Quanto à classe gramatical, grande parte dos neologismos por empréstimo pertence à classe dos substantivos, o que

4 Muito mais casos (oitenta blogues) foram descritos na monografia publicada pela autora do texto (publicação citada na bibliografia). 
confirma as considerações de Alves (1984) sobre a classe gramatical dos neologismos recebidos por empréstimo no português. Observemos que o mesmo fenómeno acontece também em polaco, apesar de ser uma língua pertencente ao grupo de línguas eslavas. O que a difere do português, é o facto de os substantivos em polaco serem declinados, por isso, reparamos muitas vezes em que os anglicismos sofrem adaptação com acréscimo das desinências dos casos. Confirmam-se, então, as considerações da linguista brasileira citada acima segundo a qual este fenómeno acontece comummente em todos os sistemas linguísticos (Alves 1984: 122). Observemos, pois, alguns exemplos que achamos mais relevantes para o nosso estudo.

\section{Exemplos do blogue brasileiro}

Um dos primeiros exemplos que selecionámos para os objetivos do presente estudo é o caso de empréstimo "animal print". Trata-se de um anglicismo bastante frequente nos blogues relacionados com a moda. O que chamou a nossa atenção, foi o facto que a autora usou o plural do lexema 'animal' como se estivesse escrito em português, mas sem fazer concordância do substantivo "print" (neste caso, a forma mais adequada parecia "animais prints", uma palavra composta híbrida):

1) “O animal print também é uma aposta legal pro festival. Dá pra usar sozinho, misturar com brilho, com estampas, ou até outros animais print. O que importa é não esquecer a atitude.” (www.garotasestupidas.com)

O nosso exemplo seguinte é o empréstimo look e devemos acrescentar que se trata de um dos empréstimos mais populares em português e em polaco dos últimos tempos, sobretudo no caso dos blogues que tratam da moda e beleza, mas não só. Funcionando como substantivo masculino, até possui a forma diminutiva aportuguesada, como no exemplo abaixo:

2) A tendência mais bombada dos últimos meses não pode ser esquecida nos lookinhos do Rock in Rio! (www.garotasestupidas.com)

No exemplo seguinte observamos como o anglicismo trend substitui o termo correspondente português 'tendência', portanto, por analogia com a forma correspondente portuguesa, adapta o artigo feminino português:

3) A trend bombou tem pouco tempo, mas vale apostar sem medo. (www.garotasestupidas. com)

4) não avisamos que a trend era uma boa?! (http://www.garotasestupidas.com/)

Referindo-nos ao aparecimento de novos objetos e fenómenos, encontrámos alguns exemplos no campo lexical de vestuário. 
5) é uma marca de shapewear, com produtos voltados para pessoas que querem valorizar as curvas do corpo (https://www.garotasestupidas.com)

O termo shapewear determina peças de roupa interior cuja função é modelar o corpo.

6) A marca avisa que as peças começam a chegar nas lojas a partir da segunda quinzena de agosto, mas já dá pra ir preparando a wishlist com nossos favoritos. (http://www.garotasestupidas.com/)

Do ponto de vista morfossintático, repare-se que o anglicismo wishlist pertence ao género feminino adquirindo o artigo "a" por analogia com a forma correspondente portuguesa 'a lista'. Outro caso parecido encontramos no exemplo seguinte: as body chains. Trata-se do nome de um colar que surgiu na Índia e que se tornou muito popular recentemente, introduzido pelas celebridades e logo adaptado pelas mulheres do mundo inteiro. Trata-se de um colar, em geral muito longo, que não decora apenas o decote, mas o corpo, icluíndo a barriga, usado fora ou debaixo da roupa.

7) Eu nunca tinha visto e apesar de até ter me aventurado nas body chains, acho difícil de entrar nessa... http://www.garotasestupidas.com/

Continuando, citamos alguns casos que achamos relevantes para o nosso estudo e que chamaram a nossa atenção durante a pesquisa no blogue.

8) Peças statement que valem o investimento no quesito fashion: saia de franjas (preta ou camurça, depende mesmo do seu gosto!), maxicolete de alfaiataria, top de tricô p\&b (dupla infalível para peças com cintura alta). (http://www.garotasestupidas.com/)

9) reparou que quase não tem vestidos na nossa seleção? Não que a coleção não tivesse, mas as peças com ideias fashion mais interessantes eram mesmo os separates, que levam vantagem ao poder se multiplicar em vários looks com o que a gente já tem no guarda-roupa! (http://www. garotasestupidas.com/)

Deve-se mencionar também que os substantivos ingleses fashion e statement desempenham a função de adjetivo (ideias fashion, peças statement, comprinhas fashion, evento fashion - outros exemplos também encontrados no blogue) o que permite à autora evitar a construção das frases mais longas e construções perifrásticas, tais como p. ex. 'relacionado com a moda', 'relativo à moda'. Uma situação parecida observa-se no exemplo seguinte em que a partícula "up" ganha significados diferentes dependentes do contexto. Usada na expressão "dar um up" significaria 'melhorar, aperfeiçoar, apurar.'

10) E olha que além dele Zoe tá cheia de acessórios pra dar um up no look praia com biquíni preto La Perla: body chain tradicional, vários anéis, pulseira, colar... http://www.garotasestupidas.com/ 


\section{Exemplos do blogue português}

Passando ao blogue português, sublinhemos que os empréstimos encontrados se referem, sobretudo, à moda e ao lifestyle. Por isso, é-nos possível citar exemplos das formas em geral híbridas como: "um grande guilty pleasure; uma sessão de styling; um efeito push-up; lavagem greencast com rotos; lavagem vintage. Há vários empréstimos relacionados com as peças de roupa, p. ex. “jeans skinny, jeans flare.” Entretanto, reparemos que, além das formas mencionadas, as calças de ganga aparecem no blogue como "as skinny, as culotte ${ }^{5}$, as flare, as capri" onde todas as formas adaptam o artigo feminino plural por analogia com o substantivo "as calças", mas nenhuma delas contém a desinência do plural, nem as palavras inglesas, nem o galicismo culotte ou o italianismo capri.

Na maioria, os exemplos encontrados pertencem à categoria de substantivo, mas, mesmo assim, conseguimos selecionar também alguns adjetivos, tais como nude ou camel.

11) Os meus tons preferidos são os dourados, nude, castanhos e, pontualmente, pretos. http:// apipocamaisdoce.sapo.pt/

12) Não se esqueçam de levar sempre um par de havaianas (mesmo no inverno, dão jeito para usar no quarto), calçado raso (ténis, sabrinas, sandálias) e um par de saltos para usar à noite, se vos apetecer (numa cor mais neutra, tipo camel, dourado, preto). http://apipocamaisdoce.sapo.pt/

Falando dos fenómenos internacionais, podemos mencionar a expressão it girl, usada igualmente em polaco, que determina uma mulher jovem e famosa por se vestir muito bem. ${ }^{6}$ Em geral, it girls são raparigas famosas que criam tendências e despertam interesse das outras mulheres, atraem a atenção graças às suas roupas e maquilhagens, ao seu estilo de vida; em geral são mode-

5 É preciso acrescentar que no caso do empréstimo culotte, a sua forma e o significado despertam algumas dúvidas durante o processo da sua classificação e verificação nos dicionários. Esta unidade lexical não foi encontrada no Dicionário da Porto Editora e nos outros dicionários consultados foi citada apenas a forma aportuguesada "culote". O substantivo pode ter vários significados que diferem dos citados no dicionário, pois nos blogues, como culotte, entende-se um tipo de calças muito largas, até ao tornozelo e em forma de A:

Definição 1: culote |s. m. ou f. $\mid$ s. m. ouf. 2 núm.

substantivo masculino ou feminino

1. O mesmo que culotes.

culotes

substantivo masculino ou feminino de dois números

2. [Vestuário] Calças largas na parte de cima e justas na parte de baixo, próprias para andar a cavalo e com as quais se usa botas de cano alto.

3. [Vestuário] Calça para uso feminino, com formato semelhante ao de uma saia e comprimento até aos joelhos.

4. [Informal] Excesso de gordura na parte lateral das ancas e das coxas.

Definição 2: culote $s m+f($ fr culotte $)$

1. Espécie de calça para montaria, muito larga na parte superior e justa a partir do joelho.

2. Concentração de gordura localizada na parte externa da parte alta das coxas.

culote s.m. Calça comprida, apertada abaixo do joelho e usada para montar a cavalo.

6 Atualmente, usa-se mais o neologismo ,influencer”, usado para determinar pessoas que têm influência nos seus observadores que tentam imitá-las. Esta forma é recente, mas em polaco já encontramos uma forma derivada feminina "influencerka." 
los, cantoras, celebridades, atrizes ou blogueiras. Portanto, em polaco existe também a forma deste empréstimo escrita com hífen, it-girl.

13) A minha e a de meio mundo, que tudo o que é fashionista, it girl e mulherio assim em geral anda a passear-se com eles. (http://apipocamaisdoce.sapo.pt/)

14) E com sucesso, que é ver tudo o que é it girl por esse mundo fora a voltar a uma moda que, possivelmente, jurou por todos os santinhos, não voltar a usar. http://apipocamaisdoce.sapo.pt/

No blogue português encontramos também alguns vocábulos relacionados com a vida de mãe, p.ex. um empréstimo que designa uma local especial destinado para os bebés.

15) Aliás, os Bahia Príncipe têm mesmo a promoção especial "Family Premium”, com quartos específicos para famílias (devidamente localizados junto das zonas de diversões dos mais pequenos), check-in especial, descontos, presentes de boas-vindas, baby station (zona especial com tudo o que os bebés precisam) e muito mais. (http://apipocamaisdoce.sapo.pt/)

O nosso exemplo seguinte é baby shower - é um evento para celebrar a chegada de um bebé e festejar a fase final da gravidez. A grávida é a pessoa mais importante da festa a quem os outros (principalmente as mulheres da família e amigas) trazem prendas para o bebé. Esta moda proveniente dos Estados Unidos tem-se tornado mais comum e popular em Portugal, no Brasil e na Polónia também.

16) Cá por casa ainda estamos a usar fraldas que nos ofereceram no baby shower. http://apipocamaisdoce.sapo.pt/

Neste campo lexical também destacamos o empréstimo "kids club", um local destinado a crianças.

17) Levar o Mateus ao kids club para queimar energias;

18) Que os quartos são óptimos e perfeitos para acolher crianças, que há imensas excursões e actividades para os miúdos (kids club, jogos, animação infantil, parques aquáticos, etc e tal) e que todo o hotel está todo muito voltado para receber famílias. http://apipocamaisdoce.sapo.pt/

A jornalista portuguesa descreve também diferentes atividades em que participa, mencionando p. ex. uma atividade de desporto canino, de origem americana.

19) Vai acontecer no próximo domingo, dia 21, no Parque Florestal de Monsanto (a partir das 9:30 junto ao anfiteatro Keil do Amaral) e inclui uma cãominhada, um picnic e uma demonstração de habilidades caninas com actividades de agility, obediência e flyball. http://apipocamaisdoce. sapo.pt/

Foi-nos possível selecionar alguns termos relacionados com a atividade física. Neste aspeto, há algumas proximidades com o blogue polaco que também trata deste assunto. Neste caso, os 
termos usados referem-se a novas modalidades desportivas, assim como efeitos negativos da prática de atividade física.

20) Depois, acho que entrei um bocadinho em overtraining (este mês já levo 150 quilómetros nas pernas) e os músculos têm-se ressentido. www.apipocamaisdoce.sapo.pt

O empréstimo designa um excesso de treinamento, quando as pessoas treinam de maneira inadequada ou sem respeitar os intervalos durante o exercício.

21) Ainda assim, decidi dar uma nova oportunidade ao paddle surf, e então lá fomos nós para a Lagoa de Óbidos. Todos, Mateus incluído (podem ir marcando o número da Comissão de Protecção de Menores). (http://apipocamaisdoce.sapo.pt/)

Remo em pé (REP), stand up paddle boarding é um desporto recentemente praticado pelos adeptos do surf, que está a tornar-se cada dia mais popular no mundo inteiro.

A blogueira usa também anglicismos nos textos relacionados à culinária, como vemos no exemplo seguinte:

22) Para casa trouxe queijo de cabra, tomate cherry, fiambre de peru e tomilho. (http://apipocamaisdoce.sapo.pt/)

O tomate cherry tem o nome português tomate-cereja. Trata-se de uma espécie de tomate de tamanho menor, usado sobretudo em saladas ou enfeites de pratos.

\section{Exemplos do blogue polaco}

Os empréstimos encontrados no blogue polaco https:/hpba.pl/blog/, escolhido para a recolha do corpus, têm o caráter um pouco diferente dos blogues em português apresentados acima. Como a autora é desportista, mas ao mesmo tempo uma celebridade, o seu blogue concentra-se, sobretudo, na atividade física e na alimentação saudável, por isso, os empréstimos selecionados são relacionados com estes assuntos (p.ex. smoothie bowl na drugie śniadanie, lunchbox). O endereço do blogue é a abreviação de "Healthy Plan by Ann", então, o nome é mais internacional do que os outros dois. Reparamos também que os títulos de secções do blogue propostas pela autora são, principalmente, ingleses ("camp by Ann", "diet by Ann”, "food”, "baby", "center", "Diet \& Training by Ann") ou formam híbridas, tais como "Healthy Mama Camp", "warsztaty Healthy Ciąża”. Não há uniformidade gramatical quanto às formas declinadas ("treningi z Healthy Team’em, coachem"; “Przygotuj się na dużo brzuszków i planków!”) Os anglicismos são usados também na descrição dos exercícios e, neste caso, também não há uniformidade quanto ao uso da língua: repare-se que a lista de exercícios recomendados começa em polaco, mas a seguir vêm termos ingleses: przysiad, wykrok, push, pill, press, plank, hinge, rotation. Também se usa o anglicismo "streching", mesmo

7 Em polaco, não se usa o itálico na grafia das palavras estrangeiras. 
que este termo tenha o equivalente polaco. Às vezes, as postagens apresentam uma verdadeira mescla de termos polacos e ingleses, que pode ser complicada para as pessoas que não conhecem a linguagem especializada relacionada com o desporto e a atividade física.

23) W każdym programie TX znajdziesz treningi o nazwie Cardio, ABS CORE, Nogi i ramiona, Whole Body, Ramiona i plecy, Karate Cardio, Challenge, Stretching. (https://hpba.pl/blog/)

Observando a linguagem usada no blogue em questão, encontramos muitas formas híbridas, em geral resultantes da ligação das palavras polacas com os anglicismos, p.ex.: gorset mięśni core, ćwiczenia typu deadlift, clean, swing z kettlebell (neste caso, o anglicismo kettlebell não foi declinado, embora, como pudemos ver acima, alguns anglicismos tenham sido adaptados às declinações em polaco). Também nos parece inovação a expressão "efekt afterburn" ("efeito afterburn"), em que o anglicismo permite evitar o uso de uma perífrase mais longa ou alguma explicação do fenómeno ("afterburn" significa que as calorias são queimadas mesmo depois de acabar de fazer o exercício físico). No mesmo blogue, encontramos outro exemplo que relacionamos com usos inadequados ou desvios. O nosso objetivo não é o de criticar ou condenar o uso inadequado, mas apenas indicar que algumas inadequações podem resultar da correção incompleta do texto. Reparemos no caso do empréstimo "burpees", também escrito "burpess".

24) Ex. 23: W ilu minutach udało Wam się wykonać Burpess?

Terminando, achamos oportuno acrescentar ainda que no caso deste blogue estamos perante o desenvolvimento da língua e da cultura geral, observamos a ligação da língua com o progresso tecnológico e o intercâmbio científico.

\section{Considerações finais}

Falando sobre os textos publicados pelas blogueiras, vale a pena mencionar que todas elas possuem também os seus perfis nas redes sociais, e as informações sobre isso aparecem também nos blogues. Especialmente um fenómeno bastante comentado é relacionado com uma rede social muito famosa, por isso, existem empréstimos ligados também a esta rede (trata-se, nomeadamente, do Instagram, uma rede social onde as pessoas partilham fotografias, chamado também de 'Insta', uma forma abreviada também frequente entre os utilizadores ${ }^{9}$ ). Um dos empréstimos mais populares dos últimos anos usado tanto em português como em polaco é follow. Follow significa 'seguimento, acompanhamento' e é um termo que se tornou popular com o aparecimento de

8 Trata-se do nome de um treino bastante complexo. Na língua portuguesa, também se usa este termo, mas a palavra surge no singular (burpee).

9 Como o Instagram se dedica sobretudo à publicação das fotografias, achamos que não nos fornece o material suficiente para a análise linguística dos empréstimos; portanto, como nos blogues aparecem muitas vezes as referências a esta rede social, achámos oportuno incluir algumas reflexões sobre o léxico relacionado com este assunto. Em polaco, Instagram serviu de base da criação de neologismos tais como "instamodelka" (modelo que publica as suas fotos no Instagram) ou "instamatka" (mãe que apresenta a sua vida perfeita e os seus filhos através desta rede social). 
Instagram. O termo derivado follower também é chamado de 'seguidor'10 na terminologia portuguesa (é uma pessoa que observa as fotografias escolhidas no Instagram); em polaco usa-se a forma correspondente "obserwujący", portanto, o anglicismo é muito frequente entre os utilizadores polacos. Em polaco, a palavra sofre adaptação e é declinada conforme as regras gramaticais polacas, p.ex. adaptando o plural "followersi", ou "mieć / zdobyć followersów" (ter / ganhar followers).

25) Pra não perder NADA do que está rolando fique de olho na hashtag \#CasaDosYoutubers e ative o follow djá. (http://www.garotasestupidas.com/).

Quando se deixa de observar alguém, é suficiente "dar unfollow". Porém, o número de followers é muito importante, não só o número de visitas no blogue, pois traz mais lucros dos contratos publicitários. ${ }^{11}$ Acrescentemos que a rede social Instagram possibilita também a publicação de "stories". Nos comentários encontrados no blogue "apipocamaisdoce" reparamos na hesitação quanto à adaptação deste empréstimo, pois as pessoas que deixaram comentários usaram artigos diferentes - foi usado o masculino "os teus stories" e o feminino "as stories". Portanto, observando outros comentários dos leitores, notamos que a forma utilizada mais frequentemente foi a feminina, o que nos permite concluir que, por analogia com o substantivo português "história", o género feminino deste substantivo vai dominar.

Observando as palavras de origem estrangeira descritas neste estudo, convém salientar que na maioria se referem aos fenómenos recentes e novas modas provenientes da cultura anglófona. A sua introdução depende das blogueiras e da sua atenção ao que acontece nas tendências atuais no mundo. Algumas possuem a história mais longa relacionada com a cultura geral, ou também são as palavras internacionais, como os termos relacionados com o desporto e a atividade física, ou também relacionados com a moda. Os exemplos reunidos permitem-nos observar as modificações ocorrentes nas sociedades contemporâneas. As blogueiras introduzem estas palavras porque correspondem também às suas necessidades: as autoras dos posts têm de ser bem informadas, reagir a cada moda que nasce no mundo para depois informar as suas leitoras e manter o contacto com elas.

O que pretendemos com este estudo é mostrar que o processo de introdução dos empréstimos na língua não deve ser considerado como um fenómeno prejudicial, mas como um fenómeno natural, uma fase pela qual a língua está a passar. As mudanças do léxico são impossíveis de parar porque cada vez há mais recursos tecnológicos e inovações técnicas. Há muitos argumentos a favor do uso dos itens lexicais estrangeiros relacionados com o desenvolvimento da língua e da cultura geral, o contacto com outras culturas, o progresso e o intercâmbio científico. As sociedades tornam-se mais modernas e mais abertas às diferenças culturais, e esta abertura tem o seu reflexo na língua também. Por isso, torna-se impossível não aceitar algumas palavras ou procurar equivalentes portugueses ou polacos: são mudanças demasiado rápidas.

10 No Instagram, Camila Coutinho tem 2500000 seguidores; Ana Garcia Martins - 365 000, e Anna Lewandowska -2400000 .

11 Segundo os dados do site https://www.e-konomista.pt/quanto-ganha-um-blogger/, ter um blogue também pode trazer boa remuneração. Se for visitado por mil pessoas por dia, cada espaço publicitário traz entre 100 e 200 euros por dia. Os bloggers famosos ganham também participando em eventos ou campanhas das marcas. Ressaltemos que o blogue de Camila Coutinho conta com 3 três milhões de visitantes por mês e tem 7, 5 milhões de visualizações mensais. 
É preciso ter em conta que o processo de emprestar as palavras é determinado por vários fatores, pois nunca acontece no vazio - acontece sempre numa situação, num momento histórico determinado e no lugar geográfico concreto. É um processo determinado pela situação política, económica e cultural de ambos (ou mais) lados que nele participam. Vale a pena sublinhar que existe uma rede de relações recíprocas entre as línguas que estão em contacto, determinada sobretudo pelo parentesco das línguas, proximidade sistemática, prestígio e importância de cada uma delas. A nossa proposta é de tentar construir o modelo "moderado", o que significa que não se pode evitar a entrada de palavras estrangeiras, mas deviam-se evitar formas estranhas e deturpadas ou inadequadas no dado contexto. Tendo em conta várias teorias relacionadas com os processos de importação de novas palavras, gostávamos de propor designações um pouco diferentes e ver a entrada das unidades lexicais estrangeiras como um processo inevitável, mas enriquecedor. Por isso, vemos as palavras estrangeiras não como loan words, mas como increment words ou gain words, como palavras adquiridas no processo de enriquecimento e de desenvolvimento da língua. Trata-se das alterações multidimensionais que devem ser consideradas em vários aspetos, por isso achamos que o tema não foi esgotado e exige a continuação da pesquisa. Os blogues e os comentários escritos pelos leitores, escritos de maneira espontânea, por existirem no espaço virtual, são abertos às alterações linguísticas, mas, por outro lado, é o que nos permite observar o estado atual da língua. Porém, não podemos ter a certeza que todas as unidades citadas vão integrar o acervo lexical do português e do polaco, portanto todas têm as suas funções nos textos escritos pelas blogueiras. Indubitavelmente, o papel das comunidades falantes e a reação dos leitores são primordiais na sua possível inclusão no português e no polaco. Dado que a Internet atualmente é uma fonte inesgotável de saber e de inspiração, a evolução e a dinamicidade das línguas são surpreendentes; o aparecimento dos blogues e das redes sociais causou uma verdadeira revolução na expressão escrita em geral, não só na introdução do novo léxico. $\mathrm{O}$ caráter heterogéneo e dinâmico da língua é bem visível na presença das unidades lexicais provenientes de diferentes línguas entre as quais se destaca o inglês, o que ficou óbvio nas nossas análises, mas reparemos que outras línguas tais como o francês ou o italiano também participam neste processo de renovação do léxico. Na nossa opinião, os itens lexicais estrangeiros saíram dos mundos específicos em que normalmente são estudados, tais como a economia, a informática, a ciência, sendo usados pelas pessoas não como palavras relacionadas com as tecnologias especializadas, mas na fala quotidiana. Apesar de existirem vozes críticas quanto aos estrangeirismos, é incontestável que o polaco e o português sempre aproveitaram os acervos lexicais das outras línguas, o que não impediu o seu desenvolvimento.

\section{Referências bibliográficas}

Alves, I. M. (1984). A integração dos neologismos por empréstimo ao léxico português. Alfa. 28, 119-126. (2004). A unidade lexical neológica: do histórico-social ao morfológico, As ciências do léxico: lexicologia, lexicografia e terminologia (pp. 77-87). Campo Grande: Editora UFMS.

Correia, M. (1999). A denominação das qualidades - contributos para a compreensão da estrutura do léxico português. Dissertação de Doutoramento, Universidade de Lisboa, Lisboa. 
Crystal, D. (2006). Language and the Internet. Cambridge-New York: Cambridge University Press.

Freitas, A. E. L. (2007). Estrangeirismos de língua inglesa (o caso dos antropônimos). Soletras, 14, 129-161.

Guilbert L. (1975). La creativité lexicale. Paris: Librairie Larousse.

Jabłonka, E. (2016). Introdução das unidades lexicais estrangeiras no português atual. Estudo baseado em blogues femininos portugueses e brasileiros. Lublin: Wydawnictwo UMCS.

Lamberti, F. (1999). Empréstimos linguísticos no Português do Brasil: uma interpelação variacionista. Dissertação de Mestrado - UnB.

Laruccio, M. M. (2014). Aspectos da Influência dos Blogs no Comportamento de Compra de Cosméticos por Mulheres. In $4^{\circ}$ Congresso Internacional em Comunicação e Consumo, 8-14 outubro, 2014. <http://www. espm.br/download/Anais_Comunicon_2014/gts/gt_seis/GT06_mauro_maia.pdf>

Myers, G. (2009). Discourse of Blog and Wiki. London-New York: Continuum.

Rio-Torto, G. M. (2006). O léxico: semântica e gramática das unidades lexicais. <http://www1.ci.uc.pt/celga/ membros/docs/textos_pdf/o_lexico.pdf>

Weinreich, U. (1988). Languages in contact: Findings and problems. The Hague: Mouton.

Wright, J. (2008). Blog marketing: a nova e revolucionária maneira de aumentar vendas, estabelecer sua marca e alcançar resultados excepcionais. São Paulo: M. Bodes.

\section{Blogues citados:}

$<$ www.apipocamaisdoce.sapo.pt $>$

$<\mathrm{http} / / / w w w . g a r o t a s e s t u p i d a s . c o m />$

$<$ https://hpba.pl/blog/>

\section{Dicionários}

Dicionário de Porto Editora on-line. <www.infopedia.pt $>$

Dicionário de Língua Portuguesa Priberam. $<$ https://dicionario.priberam.org/>

Dicionário Dicio-online. $<\mathrm{https} / /$ www.dicio.com.br/>

Dicionário Michaelis. <https://michaelis.uol.com.br/>

This work can be used in accordance with the Creative Commons BY-SA 4.0 International license terms and conditions (https://creativecommons.org/licenses/by-sa/4.0/legalcode). This does not apply to works or elements (such as images or photographs) that are used in the work under a contractual license or exception or limitation to relevant rights. 